\title{
BMJ Open An explorative study to assess the association between health-related quality of life and the recommended phase II dose in a phase I trial: idarubicin-loaded beads for chemoembolisation of hepatocellular carcinoma
}

\author{
Amélie Anota, ${ }^{1,2}$ Mathieu Boulin, ${ }^{3,4}$ Sandrine Dabakuyo-Yonli, ${ }^{1,5}$ Patrick Hillon, ${ }^{3,6}$ \\ Jean-Pierre Cercueil, ${ }^{3,7}$ Anne Minello, ${ }^{3,6}$ Jean-Louis Jouve, ${ }^{3,6}$ Xavier Paoletti, ${ }^{8}$ \\ Laurent Bedenne, ${ }^{3,6}$ Boris Guiu, ${ }^{9}$ Franck Bonnetain ${ }^{1,2}$
}

To cite: Anota A, Boulin M, Dabakuyo-Yonli S, et al. An explorative study to assess the association between health-related quality of life and the recommended phase II dose in a phase I trial: idarubicin-loaded beads for chemoembolisation of hepatocellular carcinoma. BMJ Open 2016;6:e010696. doi:10.1136/bmjopen-2015010696

- Prepublication history and additional material is available. To view please visit the journal (http://dx.doi.org/ 10.1136/bmjopen-2015010696)

Received 27 November 2015 Revised 17 May 2016 Accepted 6 June 2016 CrossMark

For numbered affiliations see end of article.

Correspondence to Amélie Anota; aanota@chu-besancon.fr

\section{ABSTRACT}

Objectives: The objective of this study was to explore the association between health-related quality of life (HRQoL) and the recommended phase 2 dose in a phase I clinical trial according to the Time to HRQoL deterioration approach (TTD).

Setting: This is a phase I dose-escalation trial of transarterial chemoembolisation (TACE) with idarubicin-loaded beads performed in cirrhotic patients with hepatocellular carcinoma. Patients had to complete the EORTC QLQ-C30 HRQoL questionnaire at baseline and at days 15, 30 and 60 after TACE.

Participants: Patients aged $\geq 18$ years with HCC unsuitable for curative treatments were evaluated for the study $(\mathrm{N}=21)$.

Primary and secondary outcome measurements: The primary objective was to determine the maximum tolerated dose (MTD) of idarubicin loaded after a single TACE session. MTD was defined as the dose level closest to that causing dose-limiting toxicity in $20 \%$ of patients. HRQoL was the secondary end point.

Results: Between March 2010 and March 2011, 9, 6 and 6 patients were included at idarubicin dose levels of 5,10 and $15 \mathrm{mg}$, respectively. Calculated MTD of idarubicin was $10 \mathrm{mg}$. At the $10 \mathrm{mg}$ idarubicin dose, patients presented a longer TTD than at $5 \mathrm{mg}$, for global health status (HR=0.91 (95\% Cl 0.18 to 4.72$)$ ), physical functioning ( $\mathrm{HR}=0.38$ (0.04 to 3.22)), fatigue ( $\mathrm{HR}=0.67$ (0.18 to 2.56)) and pain (HR=0.47 (0.05 to 4.24)).

Conclusions: These HRQOL results were consistent with the estimated MTD, with a median TTD for global health status of 41 days ( 21 to NA) at $5 \mathrm{mg}, 23$ days ( 20 to NA) at $10 \mathrm{mg}$ and 25 days ( 17 to $\mathrm{NA}$ ) at $15 \mathrm{mg}$. These results show the importance of studying $\mathrm{HRQ}$ oL in phase I trials. Trial registration number: NCT01040559; Post-results.

\section{Strengths and limitations of this study}

- This study is the first to explore the association between health-related quality of life and the recommended phase II dose in a phase I clinical trial according to the time to deterioration approach.

- Health-related quality of life was Iongitudinally assessed using the cancer-specific EORTC QLQ-C30 questionnaire during treatment.

- A high completion rate was observed at baseline and at each follow-up.

- Health-related quality of life analysis was performed for exploratory purposes as a secondary end point to this phase I clinical trial, and thus poor precision in the estimations was observed.

\section{BACKGROUND}

Hepatocellular carcinoma (HCC) is the fifth most frequent cancer, and the third most common cause of cancer-related death in the world, ${ }^{1}$ with most patients cared for in the palliative setting. In palliative care, one of the standard treatments is transarterial chemoembolisation $^{2}$ (TACE), but the prognosis of these patients remains poor. Owing to the condition of these patients in the terminal phase of disease, health-related quality of life (HRQoL) is considered as a valuable end point that is as important as overall survival, in order to investigate the clinical benefit for patients, ${ }^{3-5}$ and is critical when the likelihood of a cure is low, as in 
advanced HCC. However, to date, few studies have assessed HRQoL in patients undergoing TACE.

Protocols for TACE implementation vary widely between centres and radiologists, and idarubicin has been shown to be the most cytotoxic drug. ${ }^{6}$ In this context, a recent phase I clinical trial evaluated the safety and efficacy of TACE with idarubicin-loaded beads for the treatment of unresectable HCC. ${ }^{7}$ The primary end point was to determine the maximum tolerated dose (MTD) of idarubicin loaded in drug-eluting beads after a single TACE session. The MTD obtained was $10 \mathrm{mg}$, defined as the dose level closest to that causing dose-limiting toxicity (DLT) in $20 \%$ of patients. The DLT was determined according to the National Cancer Institute Common Terminology Criteria for Adverse Events (NCI-CTCAE) V.3.0, ${ }^{8}$ targeting grades $3 / 4$, as the types of toxicities that could be associated with treatment failure.

The duration of toxicity and/or the occurrence of late toxicity are not taken into account in the definition of DLT. Some moderate toxicities observed over a long period could impair patients' HRQoL, this is the case for the new biological agent assessed in oncology ${ }^{9}$ and could be the case for idarubicin as well. These moderate toxicities are also not taken into account in the usual definition of DLT based on the NCI-CTCAE assessed by clinicians at cycle $1 .{ }^{10}$ Therefore, the usual definition of DLT may not appropriately reflect the patient's feelings regarding the tolerability of the treatment received, resulting in overestimation or underestimation of these toxicities. ${ }^{11}{ }^{12}$ As a result, the dose actually selected for future development may not be the best recommended phase II dose (RP2D).

In this context, the added value of HRQoL as a complement to the usual NCI-CTCAE scale to detect intolerable treatments and doses deserves to be investigated. The added value of HRQoL or other patientreported outcomes to assess the safety of treatment toxicities has frequently been investigated in the last decade but, to date, it has been poorly investigated in oncology phase I clinical trials, and never in HCC to the best of our knowledge. In many phase I studies, analyses are more descriptive than longitudinal, and HRQoL results are not used to complement interpretation of results, nor to select the RP2D. ${ }^{13}$ One recent study analysed longitudinal HRQoL in a phase I clinical trial, but only compared two time points, namely, before and after treatment. ${ }^{14}$ Time to HRQoL score deterioration (TTD) ${ }^{15-17}$ could be an alternative way to analyse these data in a clinically meaningful way.

The objective of this study was to explore the association between HRQoL and RP2D in a phase I trial in patients with HCC. The TTD approach was used, with several definitions of composite end points, both including and not including the occurrence of severe toxicity (grade $3 / 4$ according to the NCI-CTCAE criteria) as assessed by the clinician.
METHODS

\section{Study objectives}

Data from a phase I, monocentric, open-label, dose-escalation study of TACE with idarubicin-loaded beads were used. All patients were fully informed of the study and provided signed written informed consent. The protocol was approved by the Ethics Committee, and written approval from the French national health products safety agency ('Agence Française de Sécurité Sanitaire des Produits de Santé') was obtained before the start of the study. The study was registered on ClinicalTrials.gov (identifier: NCT01040559). The design and results of this study have been extensively described elsewhere.

The primary objective was to determine the MTD of idarubicin loaded after a single TACE session. HRQoL was the secondary end point.

\section{Study population and design}

Patients aged $\geq 18$ years with HCC unsuitable for curative treatments were evaluated for the study. Eligibility criteria were: a confirmed diagnosis of HCC according to criteria from the European Association for the Study of the Liver, ${ }^{18}$ Child-Pugh liver function of A to B7 with neither ascites nor jaundice, and Eastern Cooperative Oncology Group (ECOG) performance status (PS) of 0-1.

Treatment consisted of a single TACE session with injection of $2 \mathrm{~mL}$ drug-eluting beads (DEBs) (DC Bead 300-500 $\mu \mathrm{m}$, Biocompatibles, Surrey, UK) loaded with idarubicin (Zavedos, Pfizer, Paris, France) at one of the five following escalating doses: 5, 10, 15, 20 or $25 \mathrm{mg}$. The starting dose level of idarubicin was $10 \mathrm{mg}$. Idarubicin dose escalation followed a likelihood approach continual reassessment method (CRM). ${ }^{19} 20$

DLT was defined as any unacceptable toxicity that was possibly, probably, or definitely attributed to treatment. Unacceptable toxicity was defined as any grade 4-5 adverse event from the following categories: allergy/ immunology, blood/bone marrow (for neutrophil and platelet count, a grade 4 adverse event was not considered a DLT if it was reversible within 7 days), cardiac arrhythmia, general cardiac, coagulation, constitutional symptoms, gastrointestinal, haemorrhage/bleeding, infection, metabolic/laboratory (except for total bilirubin defined as DLT if $>5$ times the upper limit of normal for five consecutive days and for creatine defined as a DLT if grade $\geq 3$ adverse event), musculoskeletal/soft tissue, ocular/visual, pain. For other categories of the NCI-CTCAE v3.0, any grade $\geq 3$ adverse event defined an unacceptable toxicity.

The MTD was defined as the dose level closest to that causing DLT in $20 \%$ of patients within the month after TACE. MTD was also the RP2D.

Cohorts of one patient were sequentially enrolled at one dose level on the basis of the DLT observed within the month after TACE of the previous patient. According to the CRM method, each new patient included was allocated to the dose level for which the 
probability of toxicity was the closest to the achievable dose level, that is, the current estimate of the MTD.

\section{HRQoL assessment}

HRQoL was evaluated at baseline and at days 15, 30 and 60 after TACE, using the European Organization for Research and Treatment of Cancer (EORTC) QLQ-C30 cancer-specific questionnaire. ${ }^{21}$ The 30-item QLQ-C30 measures five functional scales (physical, role, emotional, cognitive and social functioning), global health status (GHS), financial difficulties and eight symptom scales (fatigue, nausea and vomiting, pain, dyspnoea, insomnia, appetite loss, constipation and diarrhoea). ${ }^{21}$ HRQoL scores were generated according to the EORTC Scoring Manual. ${ }^{22}$ These scores vary from 0 (worst) to 100 (best) for the GHS and functional scales, and from 0 (best) to 100 (worst) for symptomatic scales. Patients completed the questionnaire fully and without assistance, and were given adequate time to complete this task.

\section{Statistical analysis}

\section{Population and statistical considerations}

Patients with at least one baseline HRQoL score available were included in the HRQoL analysis (modified intention-to-treat analysis). Prespecified targeted HRQoL dimensions were GHS, physical functioning, fatigue and pain.

Since this was a phase I clinical trial, HRQoL was evaluated for exploratory purposes as a secondary end point. Therefore, no $\mathrm{p}$ values are provided, while effect size is presented as HR with 95\% CI. A five-point difference in HRQoL scores was considered as the minimal clinically important difference (MCID) ${ }^{23}$

\section{Descriptive analysis and missing data}

Baseline clinical and sociodemographic characteristics are described as median and range for continuous variables, and number and percentage for qualitative variables.

Patients with missing baseline HRQoL questionnaires were described according to idarubicin dose level and time to last follow-up, in order to identify the missing data profile.

\section{Longitudinal analysis}

The objective was to explore the association between HRQoL and RP2D using the TTD approach. Thus, the idarubicin level doses were compared according to the TTD approach. Four definitions of TTD were investigated (see online supplementary table A1 in additional file 1):

1. The time from inclusion in the study to a first deterioration with a 5-point MCID as compared to the baseline score ${ }^{17}$

2. Then integrating all-cause death as event (corresponding to HRQoL deterioration-free survival (QFS)). ${ }^{15}$
3. The TTD in at least one HRQoL score among the four targeted HRQoL dimensions; ${ }^{16}$

4. Then integrating the occurrence of at least one grade $3 / 4$ toxicity according to the NCI-CTCAE criteria. This last definition makes it possible to include toxicity defined according to the NCI-CTCAE scale in the TTD definition.

For each composite definition, the event retained was the first event observed.

Patients with no follow-up score were censored 1 day after baseline and considered as events thereafter (sensitivity analysis).

TTD curves were estimated using the Kaplan-Meier method and described using median with 95\% CI. Univariate HR with $95 \%$ CI for 10 vs $5 \mathrm{mg}$ idarubicin dose level and univariate HR of $15 \mathrm{mg}$ vs $5 \mathrm{mg}$ idarubicin dose level were estimated using Cox models.

A longer TTD observed at the estimated RP2D, as compared to other doses, for all TTD definitions explored, would indicate that, from a patient's point of view, the RP2D could represent the optimal dose. Conversely, a longer TTD observed at a higher or lower dose than the RP2D for all TTD definitions explored could suggest that the RP2D should be adjusted to a higher or a lower level, respectively.

Univariate Cox regression analyses were conducted as exploratory analyses to investigate factors potentially influencing the last two definitions of TTD, namely:

- TTD in at least one HRQoL score;

- TTD in at least one HRQoL score or occurrence of at least one grade $3 / 4$ toxicity.

Variables tested were gender (women vs men), age (continuous variable), PS ( 1 vs 0 ), Child-Pugh class (A6 vs A5; B7 vs A5), Cancer of the Liver Italian Program (CLIP) score (2 vs $0 ; 1$. vs 0$),{ }^{24}{ }^{25}$ the Barcelona Clinic Liver Cancer (BCLC) stage ${ }^{26}$ (B vs A; $\mathrm{C}$ vs A) and the occurrence of DLT (yes vs no). Regarding the definition of TTD in at least one HRQoL score, the time to grade $3 / 4$ toxicity was also tested (as a time dependent variable) in order to investigate the impact of the occurrence of grade $3 / 4$ toxicity on HRQoL. The proportionality of risks hypothesis was checked using the Schoenfeld residuals test. ${ }^{27}$

All analyses were performed using $\mathrm{R}$ software ( $\mathrm{R}$ development Core Team. R: A Language and Environment for Statistical Computing. R Foundation for Statistical Computing, Vienna, Austria. ISBN 3-900051-07-0, http://www.R-project.org/ 2010. http://www.R-project. $\operatorname{org} /)$.

\section{RESULTS}

\section{Study population}

From March 2010 to March 2012, 21 patients were included: 9, 6 and 6 patients were treated at idarubicin dose levels of 5, 10 and $15 \mathrm{mg}$, respectively (figure 1). The median age was 64 years (range 45-79) and 18 patients were men $(86 \%)$. Eighteen patients had good ECOG PS 


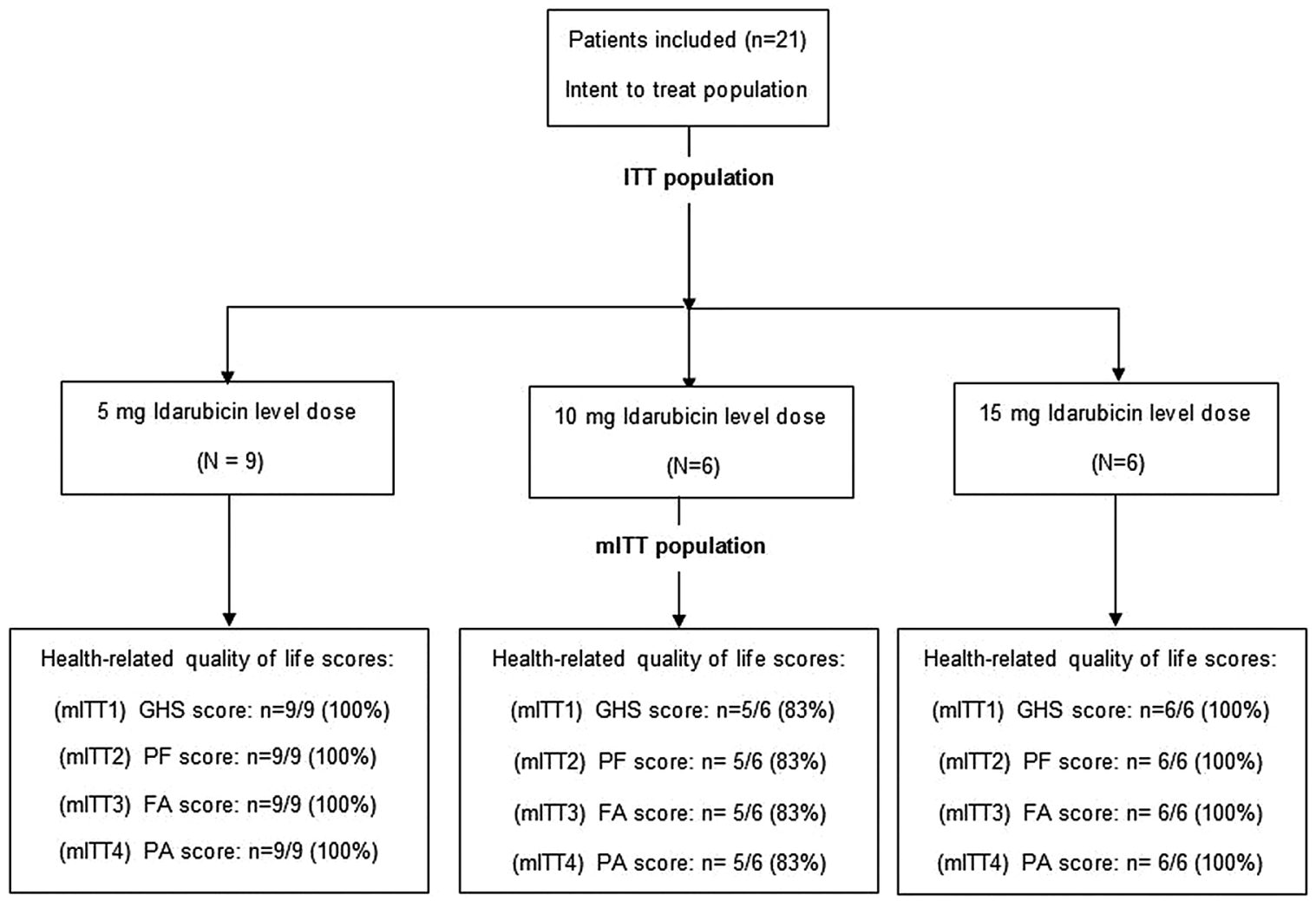

Figure 1 Consort diagram. ITT: intent to treat; mITT: modified intent to treat (ie, patients with at least the baseline HRQoL score); GHS, Global Health Status; PF, physical functioning; FA, fatigue; PA: pain.

$(86 \%)$. The baseline characteristics of the patients are summarised in table 1. DLT was observed for three patients, and the estimated MTD of idarubicin was $10 \mathrm{mg}{ }^{7}$

Twenty patients $(95 \%)$ completed the baseline HRQoL questionnaire: 18 patients $(86 \%)$ at day 15 (median time of 19 days (range 14-23)); 21 patients $(100 \%)$ at day 30 (median time of 35 days (range 29-43)) and 17 patients $(81 \%)$ at day 60 (median time of 70 days (range 64-92)) after TACE. The patient who did not complete the baseline HRQoL questionnaire was included at the $10 \mathrm{mg}$ dose level, and subsequently completed all follow-up questionnaires.

\section{Longitudinal analysis}

Table 2 displays the results of the TTD and QFS analyses according to idarubicin level dose for the four-targeted dimensions of HRQoL with the sensitivity analysis.

\section{TTD with a 5-point MCID of GHS}

Eleven patients $(55 \%)$ presented a significant deterioration of the GHS with a 5-point MCID among the 20 included patients in the longitudinal analysis (figure 2A): the median TTD was 41 days (21 to not available (NA)) at $5 \mathrm{mg}, 23$ days (20 to NA) at $10 \mathrm{mg}$ and 25 days (17 to NA) at $15 \mathrm{mg}$. The HR for $10 \mathrm{vs} 5 \mathrm{mg}$ was 0.91 (0.18 to 4.72 ). The HR for 15 vs $5 \mathrm{mg}$ was 1.60 (0.43 to 5.98 ) (table 2).

Among the 20 included patients, $14(70 \%)$ presented with significant deterioration of the GHS or death (all causes): the median QFS was 41 days (21 to NA) at $5 \mathrm{mg}, 140$ days (20 to NA) at $10 \mathrm{mg}$ and 25 days (17 to $\mathrm{NA}$ ) at $15 \mathrm{mg}$. The HR for $10 \mathrm{vs} 5 \mathrm{mg}$ was 1.35 (0.32 to 5.66 ) and 1.82 (0.47 to 6.96$)$ for 15 vs $5 \mathrm{mg}$ (table 2).

\section{TTD with a 5-point MCID of physical functioning}

Ten patients $(50 \%)$ presented a significant deterioration of physical functioning with a 5-point MCID (figure 2B): the median TTD was 42 days (21 to NA) for $5 \mathrm{mg}$, not available (23 to NA) for $10 \mathrm{mg}$ and 61 days (14 to NA) for $15 \mathrm{mg}$. The HR for 10 vs $5 \mathrm{mg}$ was 0.38 (0.04 to 3.22), and 1.07 (0.26 to 4.50) for 15 vs $5 \mathrm{mg}$ (table 2).

Integrating all-cause deaths as an event, 14 patients $(70 \%)$ presented a significant deterioration of physical functioning with a 5-point MCID or death: the median QFS was 42 days (21 to NA) for $5 \mathrm{mg}, 257$ days (23 to $\mathrm{NA}$ ) for $10 \mathrm{mg}$ and 61 days (14 to NA) for $15 \mathrm{mg}$. The HR for 10 vs $5 \mathrm{mg}$ was 0.44 (0.09 to 2.14), and 1.51 (0.41 to 5.59 ) for 15 vs $5 \mathrm{mg}$ (table 2).

\section{TTD with a 5-point MCID of fatigue}

Sixteen patients $(80 \%)$ presented a significant increase in fatigue with a 5-point MCID (figure 2C): the median TTD was 21 days (19 to NA) for $5 \mathrm{mg}, 29$ days (20 to NA) for $10 \mathrm{mg}$ and 19 days (14 to NA) for $15 \mathrm{mg}$. The HR for 10 vs $5 \mathrm{mg}$ was 0.67 (0.18 to 2.56$)$, and 1.04 (0.31 to 3.49) for $15 \mathrm{vs} 5 \mathrm{mg}$ (table 2). The same results were observed for QFS of fatigue. 
Table 1 Baseline characteristics for all patients and according to idarubicin dose $(\mathrm{N}=21)$

\begin{tabular}{|c|c|c|c|c|}
\hline Characteristic & $\begin{array}{l}\text { All patients } \\
\mathbf{N}(\%)\end{array}$ & $\begin{array}{l}5 \mathrm{mg}(\mathrm{N}=9) \\
\mathrm{N}(\%)\end{array}$ & $\begin{array}{l}10 \mathrm{mg}(\mathrm{N}=6) \\
\mathrm{N}(\%)\end{array}$ & $\begin{array}{l}15 \mathrm{mg}(\mathrm{N}=6) \\
\mathrm{N}(\%)\end{array}$ \\
\hline Age, median (range) & $64(45-79)$ & $64(45-79)$ & $65(52-74)$ & $69(51-79)$ \\
\hline \multicolumn{5}{|l|}{ Gender } \\
\hline Female & $3(14)$ & $1(11)$ & $0(0)$ & 2 (33) \\
\hline Male & $18(86)$ & $8(89)$ & $6(100)$ & $4(67)$ \\
\hline \multicolumn{5}{|l|}{ Child-Pugh class } \\
\hline $\mathrm{A} 5$ & $10(48)$ & $3(33)$ & $4(67)$ & $3(50)$ \\
\hline A6 & $6(28)$ & $2(22)$ & $2(33)$ & $2(33)$ \\
\hline B7 & $5(24)$ & $4(45)$ & $0(0)$ & $1(17)$ \\
\hline \multicolumn{5}{|l|}{ BCLC stage } \\
\hline$A$ & $5(24)$ & $0(0)$ & $1(17)$ & $4(67)$ \\
\hline B & $15(71)$ & $9(100)$ & $4(66)$ & $2(33)$ \\
\hline $\mathrm{C}$ & $1(5)$ & $0(0)$ & $1(17)$ & $0(0)$ \\
\hline \multicolumn{5}{|l|}{ CLIP score } \\
\hline 0 & $5(24)$ & $1(11)$ & $2(33)$ & $2(33)$ \\
\hline 1 & $8(38)$ & $4(44)$ & 2 (33) & 2 (33) \\
\hline 2 & 7 (33) & $4(44)$ & 2 (33) & $1(17)$ \\
\hline Missing & $1(5)$ & $0(0)$ & $0(0)$ & $1(17)$ \\
\hline \multicolumn{5}{|l|}{ Performance status } \\
\hline 0 & $18(86)$ & 8 (89) & $5(83)$ & $5(83)$ \\
\hline 1 & 3 (14) & $1(11)$ & $1(17)$ & $1(17)$ \\
\hline Number of nodules, median (range) & $2(1-6)$ & $2(1-4)$ & $4(1-6)$ & $2(1-4)$ \\
\hline
\end{tabular}

\section{TTD with a 5-point MCID of pain}

Eleven patients $(55 \%)$ presented a significant increase in pain level with a 5-point MCID (figure 2D): the median TTD was 76 days (21 to NA) for $5 \mathrm{mg}$, not available (23 to NA) for $10 \mathrm{mg}$ and 27 days (14 to NA) for $15 \mathrm{mg}$. The HR for $10 \mathrm{vs} 5 \mathrm{mg}$ was 0.47 (0.05 to 4.24), and 2.25 (0.55 to 9.14 ) for $15 \mathrm{vs} 5 \mathrm{mg}$ (table 2).

Integrating all-cause death as an event, 14 patients $(70 \%)$ presented a significant pain deterioration with a 5-point MCID or death: the median QFS was 76 days (21 to NA) for $5 \mathrm{mg}$, 257 days (23 to NA) for $10 \mathrm{mg}$ and 26 days (14 to NA) for $15 \mathrm{mg}$, respectively. The HR for 10 vs $5 \mathrm{mg}$ was 0.37 (0.08 to 1.87 ), and 2.15 ( 0.55 to 8.39) for 15 vs $5 \mathrm{mg}$ (table 2).

\section{TTD in at least one HRQoL score, with or without toxicity as an event}

Table 3 contains the results of the TTD in at least one HRQoL score, including toxicity or not, as an event with the sensitivity analysis.

Eighteen patients $(90 \%)$ presented a significant deterioration of at least one HRQoL score with a 5-point MCID: the median TTD was 31 days (19 to NA) for $5 \mathrm{mg}, 29$ days (20 to NA) for $10 \mathrm{mg}$ and 17 days (14 to $\mathrm{NA})$ for $15 \mathrm{mg}$. The HR for $10 \mathrm{vs} 5 \mathrm{mg}$ was $0.83(0.22$ to 3.17 ), and 4.47 (1.33 to 15.09) for 15 vs $5 \mathrm{mg}$ (table 3 ).

Eighteen of 20 patients $(90 \%)$ presented a significant deterioration of at least one HRQoL score with a 5-point MCID or a grade 3/4 toxicity: the median TTD was 31 days (19 to NA) for $5 \mathrm{mg}, 8$ days ( 5 to NA) for $10 \mathrm{mg}$ and 6 days ( 1 to NA) for $15 \mathrm{mg}$. The HR for $10 \mathrm{vs} 5 \mathrm{mg}$ was $0.96(0.52$ to 3.66$)$, and 3.31 (1.04 to 10.46$)$ for 15 vs $5 \mathrm{mg}$ (table 3 ).

Univariate Cox Analyses for TTD of at least one HRQoL score including toxicity or not as an event

Table 4 presents the results of the univariate Cox analyses for the TTD in at least one score with or without grade $3 / 4$ toxicity as an event and sensitivity analysis integrating no follow-up as an event.

Women presented a shorter TTD in at least one HRQoL score than men did (HR=4.39 (1.11 to 17.36)). The time to grade $3 / 4$ toxicity was also associated with a shorter TTD, whether integrating no follow-up as an event or not, and the value 1 was not included in the 95\% CI (HR=3.84 (1.31 to 11.28$)$ and $\mathrm{HR}=4.39$ (1.41 to 13.68), respectively). Surprisingly, the occurrence of DLT seemed to be associated with a longer TTD in at least one HRQoL score, integrating no follow-up as an event or not, but with a 95\% CI including $1 \quad(\mathrm{HR}=0.67$ ( 0.15 to 2.96 ) and $\mathrm{HR}=0.72$ (0.16 to 3.17 ), respectively).

\section{DISCUSSION}

The objective of this study was to explore the association between HRQoL and the RP2D in a phase I clinical trial of HCC with the time to deterioration approach.

Patients at the $10 \mathrm{mg}$ idarubicin dose level tended to present a longer time to GHS, physical functioning, fatigue and pain deterioration, as compared with patients at the $5 \mathrm{mg}$ idarubicin dose level, except for the sensitivity analysis of GHS, for which a HR (10 vs $5 \mathrm{mg}$ ) $>1$ was observed. 


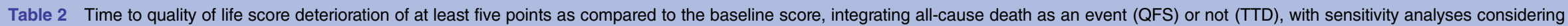
patients with no baseline score or with no follow-up score as events

\begin{tabular}{|c|c|c|c|c|c|c|c|c|c|c|c|c|}
\hline & \multicolumn{3}{|c|}{ TTD $\geq 5$-point MCID } & \multicolumn{3}{|c|}{ TTD $\geq 5$-point MCID or no follow-up } & \multicolumn{3}{|c|}{ QFS $\geq 5$-point MCID } & \multicolumn{3}{|c|}{ QFS $\geq 5$-point MCID or no follow-up } \\
\hline & $\mathrm{N}$ (events) & $\begin{array}{l}\text { Median } \\
(95 \% \mathrm{Cl})\end{array}$ & HR (95\% Cl) & $\mathrm{N}$ (events) & $\begin{array}{l}\text { Median } \\
(95 \% \mathrm{Cl})\end{array}$ & HR $(95 \% \mathrm{Cl})$ & $\mathrm{N}$ (events) & $\begin{array}{l}\text { Median } \\
(95 \% \mathrm{Cl})\end{array}$ & HR $(95 \% \mathrm{Cl})$ & $\mathrm{N}$ (events) & $\begin{array}{l}\text { Median } \\
(95 \% \mathrm{Cl})\end{array}$ & HR $(95 \% \mathrm{Cl})$ \\
\hline \multicolumn{13}{|c|}{ Global health status } \\
\hline All & $20(11)$ & 31 (21 to NA) & & $20(12)$ & 30 (21 to NA) & & $20(14)$ & 31 ( 21 to NA) & & $20(15)$ & 30 (21 to NA) & \\
\hline $5 \mathrm{mg}$ & $9(5)$ & 41 (21 to NA) & 1 & $9(5)$ & 41 (21 to NA) & 1 & $9(7)$ & 41 (21 to NA) & 1 & $9(7)$ & 41 (21 to NA) & 1 \\
\hline $10 \mathrm{mg}$ & $5(2)$ & 23 (20 to NA) & 0.91 (0.18 to 4.72$)$ & $5(3)$ & 23 (20 to NA) & $1.35(0.32$ to 5.65$)$ & $5(3)$ & 140 (20 to NA) & $1.35(0.32$ to 5.66$)$ & $5(4)$ & 23 (20 to NA) & $1.77(0.48$ to 6.62$)$ \\
\hline $15 \mathrm{mg}$ & $6(4)$ & 25 (17 to NA) & $1.60(0.43$ to 5.98$)$ & $6(4)$ & 25 (17 to NA) & 1.56 (0.64 to 5.88$)$ & $6(4)$ & 25 (17 to NA) & $1.82(0.47$ to 6.96$)$ & $6(4)$ & 25 (17 to NA) & $1.75(0.46$ to 6.66$)$ \\
\hline \multicolumn{13}{|c|}{ Physical functioning } \\
\hline All & $20(10)$ & 92 (29 to NA) & & $20(11)$ & 42 (23 to NA) & & $20(14)$ & 92 (29 to NA) & & $20(15)$ & 42 (23 to NA) & \\
\hline $5 \mathrm{mg}$ & $9(5)$ & 42 (21 to NA) & 1 & $9(5)$ & 41 (21 to NA) & 1 & $9(7)$ & $42(21$ to $N A)$ & 1 & $9(7)$ & $42(21$ to $N A)$ & 1 \\
\hline $10 \mathrm{mg}$ & $5(1)$ & $N A(23$ to $N A)$ & 0.38 (0.04 to 3.22$)$ & $5(2)$ & NA ( 23 to NA) & 0.75 (0.14 to 3.88$)$ & $5(3)$ & 257 (23 to NA) & 0.44 (0.09 to 2.14$)$ & $5(4)$ & 257 (23 to NA) & 0.67 (0.17 to 2.63$)$ \\
\hline $15 \mathrm{mg}$ & $6(4)$ & 61 (14 to NA) & 1.07 (0.26 to 4.50$)$ & $6(4)$ & 61 (14 to NA) & 1.05 (0.25 to 4.42$)$ & $6(4)$ & 61 (14 to NA) & 1.51 (0.41 to 5.59 ) & $6(4)$ & 61 (14 to NA) & $1.41(0.39$ to 5.09$)$ \\
\hline \multicolumn{13}{|c|}{ Fatigue } \\
\hline All & $20(16)$ & 21 (19 to 43 ) & & $20(17)$ & 21 (19 to 43 ) & & $20(16)$ & 21 (19 to 43 ) & & $20(17)$ & 21 (19 to 43 ) & \\
\hline $5 \mathrm{mg}$ & $9(9)$ & 21 (19 to NA) & 1 & $9(9)$ & 21 (19 to NA) & 1 & $9(9)$ & 21 (19 to NA) & 1 & $9(9)$ & 21 (19 to NA) & 1 \\
\hline $10 \mathrm{mg}$ & $5(3)$ & 29 (20 to NA) & $0.67(0.18$ to 2.56$)$ & $5(4)$ & 23 (20 to NA) & $0.90(0.27$ to 3.01$)$ & $5(3)$ & 29 (20 to NA) & 0.67 (0.18 to 2.56$)$ & $5(4)$ & 23 (20 to NA) & $0.90(0.27$ to 3.01$)$ \\
\hline $15 \mathrm{mg}$ & $6(4)$ & $19(14$ to NA) & $1.04(0.31$ to 3.49$)$ & $6(4)$ & 19 (14 to NA) & $1.02(0.31$ to 3.41$)$ & $6(4)$ & $19(14$ to $N A)$ & 1.04 (0.31 to 3.49$)$ & $6(4)$ & $19(14$ to $N A)$ & $1.02(0.31$ to 3.41$)$ \\
\hline \multicolumn{13}{|c|}{ - } \\
\hline All & $20(11)$ & 76 (23 to NA) & & $20(12)$ & 37 (21 to NA) & & $20(14)$ & 76 (23 to NA) & & $20(15)$ & 37 (21 to NA) & \\
\hline $5 \mathrm{mg}$ & $9(6)$ & 76 (21 to NA) & 1 & $9(6)$ & 76 (21 to NA) & 1 & $9(7)$ & 76 (21 to NA) & 1 & $9(7)$ & 76 (21 to NA) & 1 \\
\hline $10 \mathrm{mg}$ & $5(1)$ & NA (23 to NA) & 0.47 (0.05 to 4.24$)$ & $5(2)$ & NA (23 to NA) & $0.94(0.17$ to 5.16$)$ & $5(3)$ & 257 (23 to NA) & 0.37 (0.08 to 1.87 & $5(4)$ & 257 (23 to NA) & 0.59 (0.15 to 2.36$)$ \\
\hline $15 \mathrm{mg}$ & $6(4)$ & 27 (14 to NA) & 2.25 (0.55 to 9.14$)$ & $6(4)$ & 26 (14 to NA) & 2.14 (0.53 to 8.69$)$ & $6(4)$ & 26 (14 to NA) & 2.15 (0.55 to 8.39$)$ & $6(4)$ & 26 (14 to NA) & $1.88(0.50$ to 7.05$)$ \\
\hline
\end{tabular}




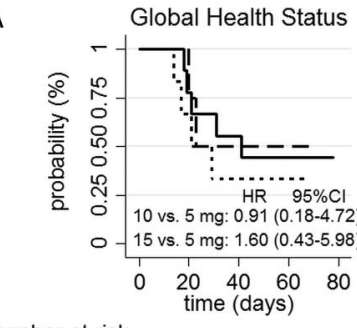

\begin{tabular}{rrrrrr} 
Number at risk \\
- & $5 \mathrm{mg} 9$ & 7 & 5 & 3 & 1 \\
-- & $10 \mathrm{mg} 5$ & 4 & 2 & 2 & 0 \\
$\cdots$ & $15 \mathrm{mg} 6$ & 4 & 2 & 2 & 0 \\
& \multicolumn{5}{c}{ Fatigue } \\
\hline
\end{tabular}

C

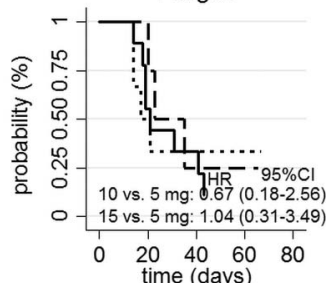

Number at risk

$\begin{array}{lr}- & 5 \mathrm{mg} 9 \\ \cdots & 10 \mathrm{mg} 5 \\ \cdots & 15 \mathrm{mg} 6\end{array}$ (days)
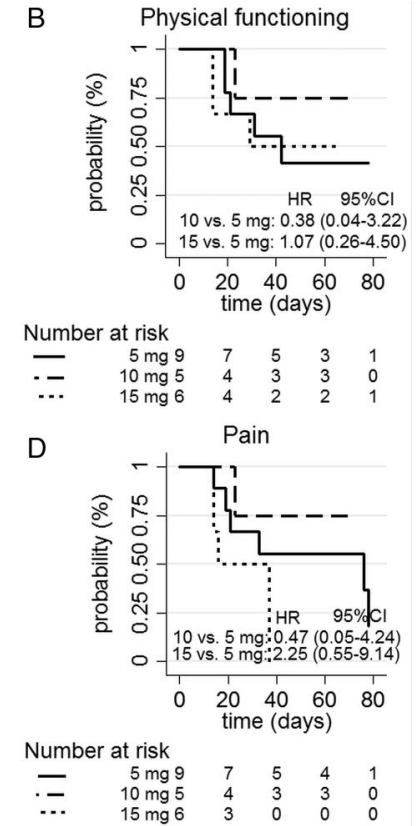

Number at risk

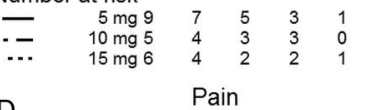

D

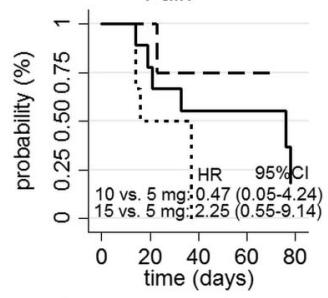

Number at risk

$\begin{array}{rr}- & 5 \mathrm{mg} 9 \\ - & 10 \mathrm{mg} 5 \\ - & 15 \mathrm{mg} 6\end{array}$
- Patients included at the $15 \mathrm{mg}$ idarubicin dose level presented a shorter TTD than those included at $5 \mathrm{mg}$, with a $\mathrm{HR}>1$.

Overall, patients included at the $10 \mathrm{mg}$ idarubicin dose level seemed to have a longer TTD of HRQoL than patients included at the $5 \mathrm{mg}$ or $15 \mathrm{mg}$ idarubicin dose levels. HRQoL results are thus consistent with the $10 \mathrm{mg}$ idarubicin dose level selected as the MTD, whereby patients included at the $10 \mathrm{mg}$ idarubicin dose level presented acceptable toxicities and a trend towards better HRQoL profile than did patients included at either the 5 or $15 \mathrm{mg}$ idarubicin dose levels, although these results were not significant. These results confirm that, from a patient's point of view, $10 \mathrm{mg}$ could represent the optimal dose, and was linked with RP2D.

Moreover, Cox analyses highlighted that the time to grade $3 / 4$ toxicity was associated with a shorter TTD in at least one HRQoL score with a HR $>1$. Thus, the occurrence of some toxicities during treatment has an impact on HRQoL. This suggests that the assessment of toxicities by the clinician is coherent with the patient's perception of their own HRQoL level. However, the occurrence of DLT seemed to be associated with a shorter TTD in at least one HRQoL score, but with the value of 1 included in the $95 \%$ CI. This divergent result could be due to the low number of patients experiencing DLT (only 3 DLT events occurred).

The main limitation of this study is the limited number of patients included, inherent to the study design (phase I clinical trial), and, consequently, poor precision in the estimations. However, this limitation also concerns the other end points, including the occurrence of toxicities. In any case, this study was performed for exploratory purposes only. All trends observed here represent a first indication of the impact of the idarubicin dose level on HRQoL, but the lack of statistical power and precision preclude any definitive conclusions. Another limitation is the limited number of ing no follow-up as an event.

Table 3 Time to deterioration in at least one health-related quality of life score considering grade 3/4 toxicity as an event or not, with sensitivity analysis considering patients with no follow-up as events

\begin{tabular}{|c|c|c|c|c|c|c|}
\hline & \multicolumn{3}{|c|}{ Deterioration in at least one HRQoL score } & \multicolumn{3}{|c|}{$\begin{array}{l}\text { Deterioration in at least one HRQoL score or grade } \\
3 / 4 \text { toxicity }\end{array}$} \\
\hline & $\mathbf{N}$ (events) & $\begin{array}{l}\text { Median days } \\
(95 \% \mathrm{Cl})\end{array}$ & HR $(95 \% \mathrm{Cl})$ & $\mathbf{N}$ (events) & $\begin{array}{l}\text { Median days } \\
(95 \% \mathrm{Cl})\end{array}$ & HR (95\% Cl) \\
\hline \multicolumn{7}{|l|}{$T T D$} \\
\hline All & $20(18)$ & 21 (19 to 42$)$ & & $20(18)$ & 17 (8 to 42$)$ & \\
\hline $5 \mathrm{mg}$ & $9(9)$ & 31 (19 to NA) & 1 & $9(9)$ & 31 (19 to NA) & 1 \\
\hline $10 \mathrm{mg}$ & $5(3)$ & 29 (20 to NA) & $0.83(0.22$ to 3.17$)$ & $5(3)$ & 8 (5 to NA) & $0.96(0.52$ to 3.66$)$ \\
\hline $15 \mathrm{mg}$ & $6(6)$ & 17 (14 to NA) & 4.47 (1.33 to 15.09$)$ & $6(6)$ & 6 (1 to NA) & 3.31 (1.04 to 10.46$)$ \\
\hline \multicolumn{7}{|c|}{ TTD or no-follow-up } \\
\hline All & $20(19)$ & $21(19$ to 41$)$ & & $20(19)$ & $14(6$ to 41$)$ & \\
\hline $5 \mathrm{mg}$ & $9(9)$ & 31 (19 to NA) & 1 & $9(9)$ & 31 (19 to NA) & 1 \\
\hline $10 \mathrm{mg}$ & $6(5)$ & 23 (20 to NA) & $1.10(0.33$ to 3.68$)$ & $5(4)$ & 8 (5 to NA) & 1.30 (0.39 to 4.34$)$ \\
\hline $15 \mathrm{mg}$ & $6(6)$ & 17 (14 to NA) & $3.95(1.20$ to 13.01$)$ & $6(6)$ & 6 (1 to NA) & 3.05 (0.98 to 9.46$)$ \\
\hline
\end{tabular}


Table 4 Univariate Cox analyses for time to deterioration in at least one score with or without grade 3/4 toxicity as an event, and sensitivity analysis integrating no follow-up as an event

\begin{tabular}{|c|c|c|c|c|}
\hline & \multicolumn{2}{|c|}{ MCID $\geq 5$ points } & \multicolumn{2}{|c|}{ MCID $\geq 5$ points or no follow-up } \\
\hline & $\mathrm{N}$ (events) & HR (95\% Cl) & $\mathrm{N}$ (events) & HR (95\% Cl) \\
\hline \multicolumn{5}{|c|}{ TTD in at least one score } \\
\hline \multicolumn{5}{|c|}{ Gender } \\
\hline men & $20(18)$ & 1 & $20(19)$ & 1 \\
\hline women & & 4.39 (1.11 to 17.36$)$ & & 3.60 (0.93 to 13.88$)$ \\
\hline Age $^{*}$ & $20(18)$ & 0.96 (0.90 to 1.02$)$ & $20(19)$ & 0.96 (0.90 to 1.02$)$ \\
\hline \multicolumn{5}{|l|}{ Performance status } \\
\hline 0 & $20(18)$ & 1 & 20 19) & 1 \\
\hline 1 & & 2.02 (0.53 to 7.63$)$ & & 1.80 (0.49 to 6.67$)$ \\
\hline \multicolumn{5}{|l|}{ Child-Pugh class } \\
\hline A5 & $20(18)$ & 1 & $20(19)$ & 1 \\
\hline A6 & & 3.69 (1.07 to 12.72$)$ & & 2.97 (0.90 to 9.79$)$ \\
\hline B7 & & 2.22 (0.67 to 7.32$)$ & & 1.86 (0.59 to 5.92$)$ \\
\hline \multicolumn{5}{|l|}{ Score CLIP } \\
\hline 0 & $19(17)$ & 1 & $19(18)$ & 1 \\
\hline 1 & & $1.26(0.32$ to 4.90$)$ & & 0.95 (0.28 to 3.27$)$ \\
\hline 2 & & 1.56 (0.38 to 6.37$)$ & & 1.17 (0.32 to 4.22$)$ \\
\hline \multicolumn{5}{|l|}{ BCLC stage } \\
\hline A & $20(18)$ & 1 & $20(19)$ & 1 \\
\hline B & & 0.53 (0.17 to 1.62$)$ & & $0.59(0.20$ to 1.80$)$ \\
\hline C & & 0.80 (0.09 to 6.99$)$ & & 0.81 (0.09 to 7.05$)$ \\
\hline \multicolumn{5}{|c|}{ Idarubicin level dose, mg } \\
\hline 5 & $20(18)$ & 1 & $20(19)$ & 1 \\
\hline 10 & & 0.83 (0.22 to 3.17$)$ & & $1.10(0.33$ to 3.68$)$ \\
\hline 15 & & 4.47 (1.33 to 15.09$)$ & & 3.95 (1.20 to 13.01$)$ \\
\hline \multicolumn{5}{|l|}{ DLT occurrence } \\
\hline No & $20(18)$ & 1 & $20(19)$ & 1 \\
\hline Yes & & $0.72(0.16$ to 3.17$)$ & & 0.67 (0.15 to 2.96$)$ \\
\hline Time to toxicity* & $20(18)$ & 4.39 (1.41 to 13.68$)$ & $20(19)$ & 3.84 (1.31 to 11.28$)$ \\
\hline \multicolumn{5}{|c|}{ TTD in at least one score or toxicity of grade $3 / 4$} \\
\hline \multicolumn{5}{|l|}{ Gender } \\
\hline Men & $20(18)$ & 1 & $20(19)$ & 1 \\
\hline Women & & $3.18(0.85$ to 11.86$)$ & & 2.81 (0.76 to 10.3$)$ \\
\hline $\mathrm{Age}^{\star}$ & $20(18)$ & $0.98(0.93$ to 1.03$)$ & $20(19)$ & $0.97(0.92$ to 1.03$)$ \\
\hline \multicolumn{5}{|l|}{ Performance status } \\
\hline 0 & $20(18)$ & 1 & $20(19)$ & 1 \\
\hline 1 & & 1.55 (0.42 to 5.76$)$ & & 1.39 (0.38 to 5.09$)$ \\
\hline \multicolumn{5}{|l|}{ Child-Pugh class } \\
\hline A5 & $20(18)$ & 1 & $20(19)$ & 1 \\
\hline A6 & & $3.82(1.04$ to 14.01$)$ & & 2.98 (0.86 to 10.34$)$ \\
\hline B7 & & 1.89 (0.57 to 6.23$)$ & & $1.59(0.50$ to 5.05$)$ \\
\hline \multicolumn{5}{|l|}{ Score CLIP } \\
\hline 0 & $19(17)$ & 1 & $19(18)$ & 1 \\
\hline 1 & & $1.20(0.35$ to 4.11$)$ & & $0.94(0.30$ to 2.98$)$ \\
\hline 2 & & $1.49(0.40$ to 5.51$)$ & & 1.15 (0.34 to 3.92$)$ \\
\hline \multicolumn{5}{|l|}{ BCLC stage } \\
\hline A & $20(18)$ & 1 & $20(19)$ & 1 \\
\hline B & & 0.34 (0.11 to 1.08$)$ & & $0.40(0.13$ to 1.22$)$ \\
\hline C & & $1.10(0.12$ to 9.84$)$ & & $1.06(0.12$ to 9.35$)$ \\
\hline \multicolumn{5}{|c|}{ Idarubicin level dose, mg } \\
\hline 5 & $20(18)$ & 1 & $20(19)$ & 1 \\
\hline 10 & & $0.96(0.25$ to 3.66$)$ & & 1.30 (0.39 to 4.34$)$ \\
\hline 15 & & 3.31 (1.04 to 10.46$)$ & & 3.05 (0.98 to 9.46$)$ \\
\hline \multicolumn{5}{|l|}{ DLT occurrence } \\
\hline No & $20(18)$ & 1 & $20(19)$ & 1 \\
\hline Yes & & 1.05 (0.29 to 3.81$)$ & & 0.98 (0.27 to 3.54$)$ \\
\hline
\end{tabular}

*Time dependent variable.

tContinuous variable.

BCLC, Barcelona Clinic Liver Cancer; CLIP, Cancer of the Liver Italian Program; DLT, dose-limiting toxicity; MCID, minimal clinically important difference; TTD, time to HRQoL score deterioration. 
measurement times (only four measures), which could also explain the low number of events observed for TTD, and the unavailability of median TTD. In future phase I clinical trials, more measurement times should be added in order to better capture longitudinal trends in HRQoL. Variability in the measurement time was also observed, due to logistical constraints in some hospitals in performing TACE.

Several definitions of TTD were explored, of which some included toxicity as an event, and some did not. For the composite definition, the treatment effect should be the same on each component in order to be valid (deterioration of HRQOL and toxicity).

Our results suggest that HRQoL data complement previous results obtained on toxicity, as assessed by the NCI-CTCAE scale, and consolidate the selection of the RP2D. Thus, the added value of HRQoL in phase I clinical trials could be also considered, since it may help to improve the accuracy and definition of the RP2D for future development. Of course, the objective of future phase I clinical trials should not be to optimise TTD instead of finding the highest dose with acceptable toxicity. Rather, the aim should be to complement classical dose-finding analysis with additional HRQoL analysis, in order to determine whether the analysis of HRQoL can help to confirm the RP2D, or to capture potentially unlisted effects.

The RP2D is classically based on the occurrence of limiting grade $3 / 4$ toxicities according to the NCI-CTCAE scale. This scale was initially developed for cytotoxic chemotherapies administered in a limited number of chemotherapy cycles including rest periods. Molecular targeted agents are generally given over long periods with continuous schedules. Moderate toxic side effects persisting over a long period have been shown to be frequent, and are not considered as DLT events, even if they affect the patient's daily life. ${ }^{10}$ Moreover, the assessment made by clinicians generally results in underestimation or overestimation of patients' side effects. ${ }^{28}$ In this way, patient self-reported assessment of toxicity could be considered to be more accurate than the clinician's assessment. ${ }^{29}$ In this regard, a patient-reported outcomes version of the common terminology criteria for adverse events (PRO-CTCAE) was recently developed by the National Cancer Institute. ${ }^{30} 31$ Although this new scale allows patient self-assessment of toxicity, it nevertheless will not solve the issue of moderate toxic side effects persisting over a long-period, which can have an impact on patients' HRQoL. In this context, HRQoL assessment, as well as other patient-reported symptoms, could be very helpful in a phase I clinical trial to take into account the patient's perception of the tolerability of the treatment received. ${ }^{9}$ In this study, HRQoL was assessed up to 2 months after TACE, while DLT was defined based on toxicities observed up to 1 month after TACE. It seems important, in other phase I studies, to take into account treatment side effects and their impact on the patient's HRQoL in the long term, since molecular targeted agents are expected to be delivered over long periods. It can also help to better preserve HRQoL in phase II clinical trials, if the planned dose is adapted and if supportive care is also provided.

In the TTD approach used to analyse longitudinal HRQoL, the middle dose presented the longest TTD for most of the definitions of deterioration investigated. This method may be appropriate under the assumption of a monotone increasing dose-efficacy relationship and, indeed, this is the assumption behind the main statistical models for longitudinal HRQoL analysis. It is expected that the TTD increases as efficacy increases, and then decreases as toxicity increases. Since we are looking for a balance between toxicity/efficacy, TTD can be a useful way to capture this balance.

To the best of our knowledge, this is the first study to investigate TTD in a HRQoL score in the framework of a phase I oncology clinical trial. Several studies have investigated HRQoL in phase I clinical trials, but results are generally descriptive and poorly exploited regarding the primary objective of the phase I trial. ${ }^{13}$ To the best of our knowledge, no study to date has compared the HRQoL score according to the molecular dose level allocated to the patient, and the occurrence or not of toxicity or DLT. This study represents a first approach to exploring the added value of HRQoL in phase I clinical trials, but research and reflection about the assessment of HRQoL or other patient-reported outcomes in phase I clinical trials need to be refined.

The QLQ-C30 questionnaire used in this study may not be the most appropriate HRQoL tool for patients included in a phase I trial. The development of a specific HRQoL questionnaire-more focused on symptoms - for phase I oncology trials could thus be necessary in order to capture all the relevant information regarding this specific category of patients.

\section{CONCLUSIONS}

To conclude, this study highlights that patients with HCC undergoing TACE at the $10 \mathrm{mg}$ idarubicin dose level, corresponding to the MTD, mainly presented a trend towards longer TTD than patients included at the 5 or $15 \mathrm{mg}$ doses, regardless of the definition of deterioration applied, although the differences were not significant. This study suggests the added value of patient-reported symptoms and HRQoL of patients as a complement to the usual toxicity assessment and DLT definition. Finally, an improvement in patient HRQoL could encourage better compliance with treatment. ${ }^{32}$

\section{Author affiliations}

${ }^{1}$ Quality of Life in Oncology National Platform, Besançon, France

${ }^{2}$ Methodological and Quality of Life in Oncology Unit (INSERM UMR 1098), University Hospital of Besançon, Besançon, France

${ }^{3}$ INSERM U866, University of Burgundy, Dijon, France

${ }^{4}$ Department of Pharmacy, University Hospital, Dijon, France

${ }^{5}$ Biostatistics and Quality of Life Unit (EA 4184), Centre Georges Francois Leclerc, Dijon, France 
${ }^{6}$ Department of Hepatogastroenterology, University Hospital, Dijon, France ${ }^{7}$ Department of Interventional Radiology, University Hospital, Dijon, France ${ }^{8}$ Department of Biostatistics and Epidemiology, Institut Gustave Roussy, Paris, France

${ }^{9}$ Department of Radiology, St-Eloi University Hospital, Montpellier, France

Acknowledgements The authors thank Fiona Ecarnot for correcting the manuscript.

Contributors AA performed the statistical analyses and interpretation and wrote the manuscript; $\mathrm{MB}$ designed the study, wrote the protocol, interpreted the data and reviewed the draft; PH, J-PC, AM, J-LJ, LB and BG designed the study and included the patients; SD-Y and XP interpreted the data and reviewed the draft; FB wrote the protocol, oversaw the statistical analyses, interpreted the data and reviewed the draft. All the authors read and approved the final manuscript for publication.

Funding This work was supported by a grant in the call for projects (AOI Boulin 2009) of the Clinical Research Unit of Dijon University Hospital and from the Conseil Régional de Bourgogne.

Competing interests None declared.

Patient consent Obtained.

Ethics approval Comité de Protection des Personnes Est I and the Agence Française de Sécurité Sanitaire des Produits de Santé.

Provenance and peer review Not commissioned; externally peer reviewed.

Data sharing statement No additional data are available.

Open Access This is an Open Access article distributed in accordance with the Creative Commons Attribution Non Commercial (CC BY-NC 4.0) license, which permits others to distribute, remix, adapt, build upon this work noncommercially, and license their derivative works on different terms, provided the original work is properly cited and the use is non-commercial. See: http:// creativecommons.org/licenses/by-nc/4.0/

\section{REFERENCES}

1. Ferlay J, Shin HR, Bray F, et al. Estimates of worldwide burden of cancer in 2008: GLOBOCAN 2008. Int J Cancer 2010;127:2893-917.

2. Wood TF, Rose DM, Chung M, et al. Radiofrequency ablation of 231 unresectable hepatic tumors: indications, limitations, and complications. Ann Surg Oncol 2000;7:593-600.

3. Eltawil KM, Berry R, Abdolell M, et al. Quality of life and survival analysis of patients undergoing transarterial chemoembolization for primary hepatic malignancies: a prospective cohort study. HPB (Oxford) 2012;14:341-50.

4. Ahmed S, de Souza NN, Qiao W, et al. Quality of life in hepatocellular carcinoma patients treated with transarterial chemoembolization. HPB Surg 2016;2016:6120143.

5. Doffoël M, Bonnetain $\mathrm{F}$, Bouché $\mathrm{O}$, et al. Multicentre randomised phase III trial comparing Tamoxifen alone or with Transarterial Lipiodol Chemoembolisation for unresectable hepatocellular carcinoma in cirrhotic patients (Fédération Francophone de Cancérologie Digestive 9402). Eur J Cancer 2008;44:528-38.

6. Boulin M, Guiu S, Chauffert B, et al. Screening of anticancer drugs for chemoembolization of hepatocellular carcinoma. Anticancer Drugs 2011;22:741-8.

7. Boulin M, Hillon P, Cercueil JP, et al. Idarubicin-loaded beads for chemoembolisation of hepatocellular carcinoma: results of the IDASPHERE phase I trial. Aliment Pharmacol Ther 2014;39:1301-13.

8. National Cancer Institute. Common Terminology Criteria for Adverse Events v3. 0 (CTCAE). Cancer Therapy Evaluation Program, 2006.

9. Postel-Vinay S, Arkenau HT, Olmos D, et al. Clinical benefit in phase-I trials of novel molecularly targeted agents: does dose matter? Br J Cancer 2009;100:1373-8.
10. Le Tourneau C, Razak AR, Gan HK, et al. Heterogeneity in the definition of dose-limiting toxicity in phase I cancer clinical trials of molecularly targeted agents: a review of the literature. Eur $J$ Cancer 2011;47:1468-75.

11. Basch E. Patient-reported outcomes in drug safety evaluation. Ann Oncol 2009;20:1905-6.

12. Verweij J, Disis ML, Cannistra SA. Phase I studies of drug combinations. J Clin Oncol 2010;28:4545-6.

13. Stephenson CM, Levin RD, Spector T, et al. Phase I clinical trial to evaluate the safety, tolerability and pharmacokinetics of high-dose intravenous ascorbic acid in patients with advanced cancer. Cancer Chemother Pharmacol 2013;72:139-46.

14. Rouanne M, Massard C, Hollebecque A, et al. Evaluation of sexuality, health-related quality-of-life and depression in advanced cancer patients: a prospective study in a phase I clinical trial unit of predominantly targeted anticancer drugs. Eur $J$ Cancer 2013;49:431-8.

15. Anota A, Hamidou Z, Paget-Bailly S, et al. Time to health-related quality of life score deterioration as a modality of longitudinal analysis for health-related quality of life studies in oncology: do we need RECIST for quality of life to achieve standardization? Qual Life Res 2015;24:5-18.

16. Bonnetain F, Dahan L, Maillard E, et al. Time until definitive quality of life score deterioration as a means of longitudinal analysis for treatment trials in patients with metastatic pancreatic adenocarcinoma. Eur J Cancer 2010;46:2753-62.

17. Hamidou Z, Dabakuyo TS, Mercier M, et al. Time to deterioration in quality of life score as a modality of longitudinal analysis in patients with breast cancer. Oncologist 2011;16:1458-68.

18. Bruix J, Sherman M, Llovet JM, et al. Clinical management of hepatocellular carcinoma. Conclusions of the Barcelona-2000 EASL conference. European Association for the Study of the Liver. $J$ Hepatol 2001;35:421-30.

19. O'Quigley J, Pepe M, Fisher L. Continual reassessment method: a practical design for phase 1 clinical trials in cancer. Biometrics 1990;46:33-48.

20. O'Quigley J, Shen LZ. Continual reassessment method: a likelihood approach. Biometrics 1996;52:673-84.

21. Aaronson NK, Ahmedzai S, Bergman B, et al. The European Organization for Research and Treatment of Cancer QLQ-C30: a quality-of-life instrument for use in international clinical trials in oncology. J Natl Cancer Inst 1993;85:365-76.

22. Fayers PM, Aaronson NK, Bjordal K, et al. EORTC QLQ-C30 scoring manual. 3rd edn. Brussels: EORTC 2001 ed2001. 2001.

23. Osoba D, Rodrigues G, Myles J, et al. Interpreting the significance of changes in health-related quality-of-life scores. $J$ Clin Oncol 1998;16:139-44.

24. A new prognostic system for hepatocellular carcinoma: a retrospective study of 435 patients: the Cancer of the Liver Italian Program (CLIP) investigators. Hepatology 1998;28:751-5

25. Llovet JM, Bruix J. Prospective validation of the Cancer of the Liver Italian Program (CLIP) score: a new prognostic system for patients with cirrhosis and hepatocellular carcinoma. Hepatology 2000;32:679-80.

26. Llovet JM, Bru C, Bruix J. Prognosis of hepatocellular carcinoma: the BCLC staging classification. Semin Liver Dis 1999;19:329-38.

27. Schoenfeld D. Partial residuals for the proportional hazards regression model. Biometrika 1982;69:239-41.

28. Atkinson TM, Li Y, Coffey CW, et al. Reliability of adverse symptom event reporting by clinicians. Qual Life Res 2012;21:1159-64.

29. Basch $\mathrm{E}$. The missing voice of patients in drug-safety reporting N Engl J Med 2010;362:865-9.

30. Basch E, Reeve BB, Mitchell SA, et al. Development of The Nationa Cancer Institute's patient-reported outcomes version of the common terminology criteria for adverse events (PRO-CTCAE). J Natl Cancer Inst 2014;106:pii: dju244.

31. Dueck AC, Mendoza TR, Mitchell SA, et al. Validity and reliability of the US National Cancer Institute's Patient-Reported Outcomes Version of the Common Terminology Criteria for Adverse Events (PRO-CTCAE). JAMA Oncol 2015;1:1051-9.

32. McCarberg BH, Barkin RL. Long-acting opioids for chronic pain: pharmacotherapeutic opportunities to enhance compliance, quality of life, and analgesia. Am J Ther 2001;8:181-6. 